\title{
Function of a debris-flow brake
}

\author{
Yutaka GONDA \\ ${ }^{1}$ Fac. of Agriculture, Niigata University (2-8050 Ikarashi, Nishi-ku, Niigata, Niigata 9502181, Japan)
}

\begin{abstract}
A debris-flow brake is an erosion control facility designed to stop debris flows. However, the mechanism of the debris-flow brake has not been explained. This study discusses the change in pore-water pressure near the deck of a debris-flow brake which controls solid friction between the debris flow and the deck. A dynamic model that describes the behavior of debris flows at the debris-flow brake was built It incorporates not only the change in sediment concentration of the debris flow due to water draining through the debris-flow brake but also the resulting change in pore-water pressure. Numerical simulations and experiments examined the behavior of debris flows at a debris-flow brake. The simulation and experimental results agreed. The simulation results show that the change in pore-water pressure plays an important role in how a debris-flow brake stops debris flows.
\end{abstract}

\section{INTRODUCTION}

A debris-flow brake is a unique sediment-control facility designed to stop debris flows. It consist of a "screen" which is a flat drain-like deck placed horizontally over the river channel (Fig. 1). When a debris flow crosses the deck of the debris-flow brake, the speed of the debris flow declines rapidly and it then stops (Fig. 2).

Prof. Noriaki Hashimoto of the Nagoya Institute of Technology conceived the debris-flow brake in 1956. The idea was verified experimentally by the Public Works Research Institute(PWRI), which was managed by then Ministry of Construction. Debris-flow brakes were tested in three pilot projects in Japan to gather data and technical know-how regarding their construction and maintenance. A full-scale project was implemented at Mt. Tokachidake, Hokkaido, Japan [ICHARM, 2008]. However, few debris-flow brake have been constructed recently because local residents tend not to trust the efficacy of the structure, preferring wall-type concrete sabo dams because they appear stronger and better able to trap debris flow [Mizuyama, 2008].

Debris-flow brakes are considered to to prevent sediment-related disasters efficiently in mountain terrain and residential areas, especially in developing countries, because they are cost-efficient, simply designed and easily repaired and maintained if their size and location are well planned before construction [ICHARM, 2008].

Experimental studies of the practical application of debris-flow brakes, such as a study to evaluate the optimal length of the deck, have been conducted
[ICHARM, 2008; Izumi et al., 1982; Yazawa et al., 1998]. However the detailed mechanism of the debris-flow brake is not clear from a dynamic view point [Mizuyama, 2008; Izumi et al., 1982]. The simple explanation of the mechanism is that separation of pore water in the debris flow from the sediment stops the debris flow [ICHARM, 2008; Yazawa et al., 1998; Kiyono et al., 1986; Imai et al., 1989].

It is thought that two phenomena occur when a debris flow crosses a debris-flow brake: the pore (mud) water drains through the deck of the debris-flow brake and the pore water pressure near the deck changes. Drainage of the pore water through the deck increases the sediment concentration of the debris flow increasing the bottom shear stress of the debris flow. Because the deck of the debris-flow brake is open to the air, the pore-water pressure of the debris flow near the deck decreases instantly. The decrease in pore-water pressure near the deck increases the solid friction between the debris flow and the deck.

To examine the mechanism of debris-flow brakes dynamically, this study developed a dynamic model that describes the behavior of debris flows on debris-flow brakes, while considering the change in both sediment concentration and pore-water pressure. The behavior of a debris flow in an experimental channel with a debris-flow brake was simulated under various conditions, using the model to identify the major factors controlling the behavior of debris flows on the debris-flow brake. Experiments using an experimental channel with a debris-flow brake were also conducted on the same conditions as in the simulations. The results of the simulations and experiments were compared to examine validity of the dynamic model. 


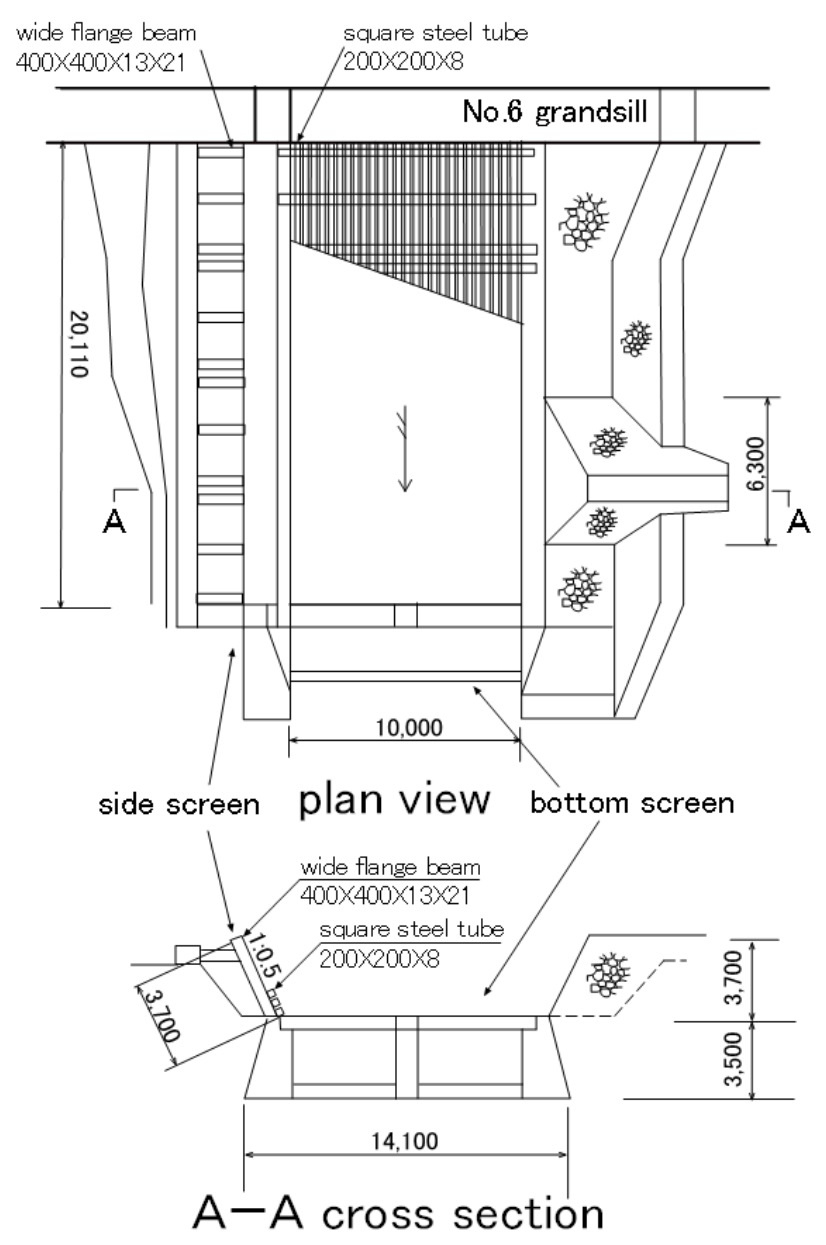

Fig. 1 Structure of the debris-flow brake in Kamikamihori Valley, Mt. Yakedake, Nagano Prefecture, Japan [Kiyono et al. , 1986].

\section{DYNAMIC MODEL OF DEBRIS FLOWS ON A DEBRIS-FLOW BRAKE}

The dynamic model of debris flow on a debris-flow brake considers both the draining of the pore water and the change in pore-water pressure. The model was based on the following assumptions and simplicifications.

\subsection{Drainage of pore water through the deck of the debris-flow brake}

Only pore water drains through the deck of the debris-flow brake, until the volumetric concentration of sediment(gravel) $c$ reaches the volumetric concentration of sediment in the sediment concentration by volume in the non-flowing layer $c *(=0.52)$. It is thought that the drainage rate per unit area $\mathrm{w}$ is $\sqrt{2 g h}$ at most, where $\mathrm{w}$ is given by Eq. (1) $w=\left\{\begin{array}{cc}0 & \text { (on the river bed) } \\ \alpha \sqrt{2 g h} & \text { (on the debris flow breaker) }\end{array}\right.$ where $\alpha$ is a parameter related to the permeability of

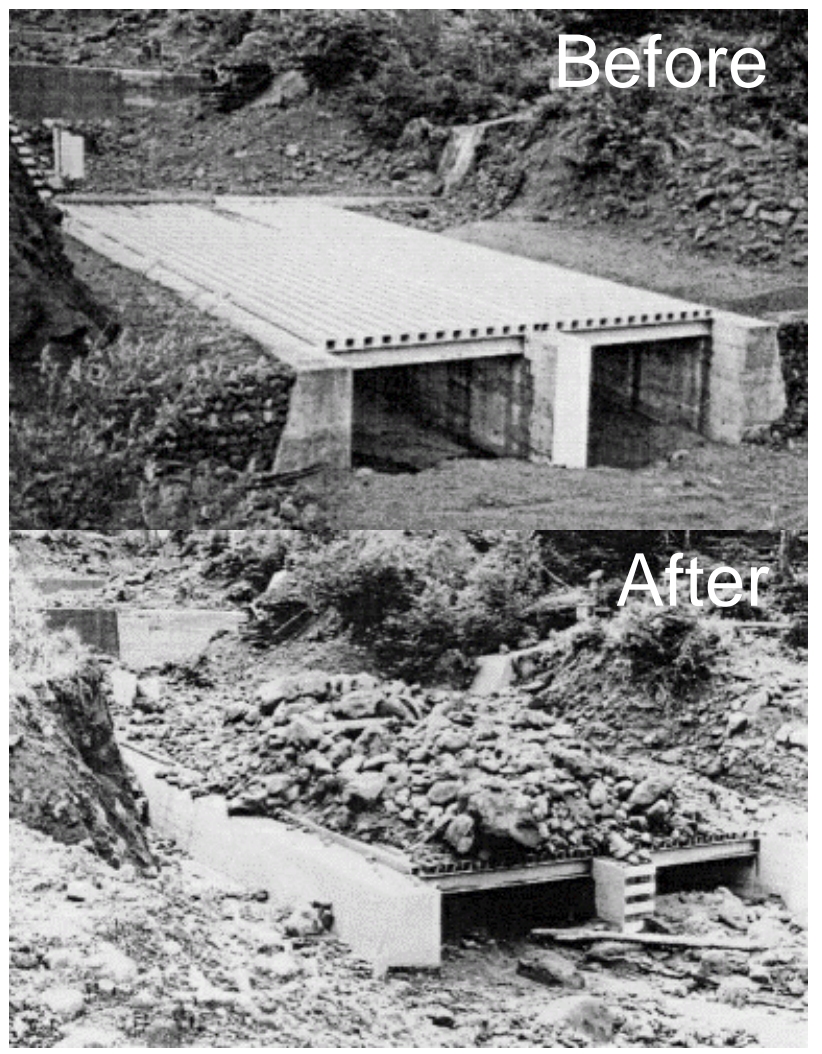

Fig. 2 The debris-flow brake in the Kamikamihori Valley, Mt. Yakedake, Nagano Prefecture, Japan (Courtesy of and copyright by Matsumoto Sabo Office, Ministry of Land, Infrastructure, Transport and Tourism Hokuriku Regional Development Bureau)

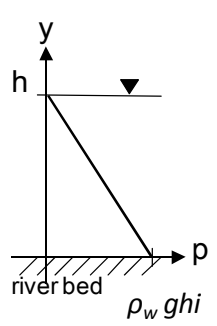

(1) On the river bed

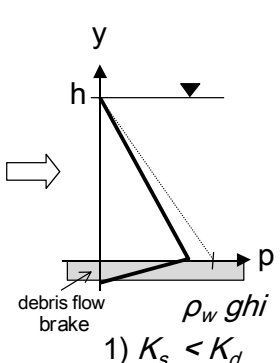

(2) On the debris flow brake

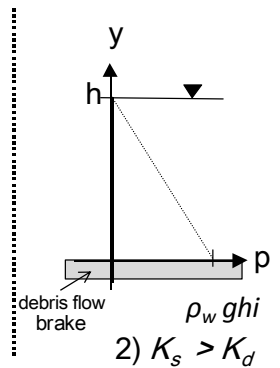

2) $K_{s}$
Fig. 3 Pore water pressure distribution of the debris flow

both the deck of debris-flow brake and of the sediment pores of the debris flow near the deck $(<1)$, $g$ is the acceleration due to gravity and $h$ is the depth of the debris flow.

\subsection{Change in pore water pressure}

The distribution of pore-water pressure on the channel bed should equal the hydrostatic pressure distribution. However, when a debris flow crosses a debris-flow brake, the pore-water pressure of the debris flow at the deck surface $(y=0)$ instantly changes to equal the pressure in air $(=0)$ because the deck of the debris-flow brake is open to the air. After 
the pore water starts to drain, the pore-water pressure depends on the permeability of the deck of the debris-flow brake and that of the sediment pores near the deck.

When the permeability of the deck of the debris-flow brake, $K_{s}$, is less than that of the sediment pores near the deck, $K_{d}\left(K_{s}<K_{d}\right)$, the pore-water pressure distribution is as shown in Figure 3, i.e., the pressure is 0 at the surface of the deck, but remains positive inside of the flow.

When $K_{s}$ is greater $K_{d}\left(K_{s}>K_{d}\right)$, the pore-water pressure equals the pressure of air $(=0)$ over the entire thickness of the flow.

The yield shear stress of a debris flow is proportional to the pressure due to static contact between sediment particles in the debris flow (Eq.(2))[Egashira et al., 1997].

$$
\tau_{y}=p_{s} \tan \phi_{s}
$$

where $\tau_{y}$ is the yield stress, $p_{s}$ is the pressure due to static contact between particles, and $\varphi_{s}$ is the friction angle of gravel.

For a steady, uniform debris flow, momentum conservation equations lead to the following relationship for the isotropic total pressure, $p$

$$
\begin{aligned}
p & =\int_{y}^{h}\left\{\left(\sigma-\rho_{w}\right) c+\rho_{w}\right\} g \cos i d y \\
& =\left\{\left(\sigma-\rho_{w}\right) c+\rho_{w}\right\}(h-y) g \cos i
\end{aligned}
$$

where $h$ is the flow depth, $i$ is the inclination of the river bed or the deck of the debris-flow brake, $\rho_{w}$ is the mass density of water, and $c$ is the volumetric concentration of sediment.

Egashira et al. [1989; 1997a; 1997b] proposed the following expression for $p$.

$$
p=p_{s}+p_{d}+p_{w}
$$

where $p_{d}$ is the dynamic pressure due to inelastic particle-to-particle collisions and $p_{w}$ is the hydrostatic pressure of pore water.

Moreover, they gave the following relationship between $p_{s}$ and $p_{d}$ [Egashira et al., 1997a ; 1997b].

$$
p_{s} /\left(p_{s}+p_{d}\right)=\left(c / c_{*}\right)^{1 / n}
$$

where $c *$ is the sediment concentration by volume in the non-flowing layer, and $n$ is an empirical constant $(=5.0)$

Substituting Eqs.(3) and (5) into Eq.(4) yields

$$
\begin{aligned}
& p_{s}=\left(c / c_{*}\right)^{1 / 5}\left[\rho g(h-y) \cos i-p_{w}\right] \\
& \rho=(\sigma-\rho) c+\rho_{w}
\end{aligned}
$$

where $\rho$ is the mass density of the debris flow, and $\sigma$ is the density of the sediment particles in the debris flow.

Substituting Eq.(6) into Eq.(2) yields

$$
\tau_{s}=\left(c / c_{*}\right)^{1 / 5}\left[\rho g(h-y) \cos i-p_{w}\right] \tan \phi_{s}
$$

Equation (8) means that a decrease in the pore-water pressure of the debris flow increases the yield stress of the debris flow. For example, if the pore-water pressure at the bottom of the debris flow decreases from $\rho g h \cos i$ to $\gamma \rho g h \cos i$ when the debris flow crosses a debris-flow brake, then the yield stress of the debris flow at the bottom of the debris flow, $\tau_{y 0}$, increases by

$$
\begin{array}{r}
\left(c / c_{*}\right)^{1 / 5}(1-\gamma) \rho_{w} g h \cos i \tan \phi_{s} \text { (Eq.(9)). } \\
\tau_{y 0}=\left\{\begin{array}{c}
\left(c / c_{*}\right)^{1 / 5}\left(\rho-\rho_{w}\right) g h \cos i \tan \phi_{s} \\
\text { (on the river bed) } \\
\left(c / c_{*}\right)^{1 / 5}\left(\rho-\gamma \rho_{w}\right) g h \cos i \tan \phi_{s} \\
\text { (on the debris flowbraker) }
\end{array}\right.
\end{array}
$$

where $\varphi_{s}$ is the friction angle of gravel, $\gamma$ is a parameter related to the change in the pore-water pressure.

2.3 Relations among $\gamma$, the permeability of the screen $K_{s}$, and the sediment pores near the deck of the debris-flow brake $K_{d}$

It is thought that $\gamma$ is a function of the permeability of the deck of the debris-flow brake $K_{s}$ and of the sediment pores near the deck of the debris-flow brake $K_{d}$, which satisfies the following boundary conditions.

$$
\begin{array}{ll}
\gamma=1 & \left(K_{s}=0\right) \\
\partial \gamma / \partial\left(K_{s} / K_{d}\right)<0 & \left(K_{s}<K_{d}\right) \\
\gamma=0 & \left(K_{s} \geq K_{d}\right)
\end{array}
$$

In this study relationship among $\gamma, K_{s}$ and $K_{d}$ is given simply by Eq.(13)

$$
\gamma=\left\{\begin{array}{cc}
0 & \left(K_{s} \geq K_{d}\right) \\
1-\left(K_{s} / K_{d}\right) & \left(K_{s}<K_{d}\right)
\end{array}\right.
$$

\section{NUMERICAL SIMULATION}

\subsection{Governing equations}

The following set of governing equations was used to conduct a one-dimensional depth-averaged numerical simulation of debris flow on a debris-flow brake.

Continuity equation:

$$
\frac{\partial h}{\partial t}+\frac{\partial(u h)}{\partial x}=w
$$




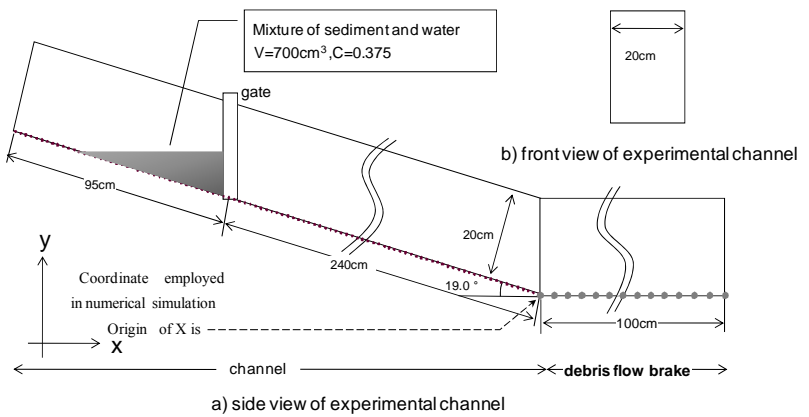

Fig. 4 Experimental channel

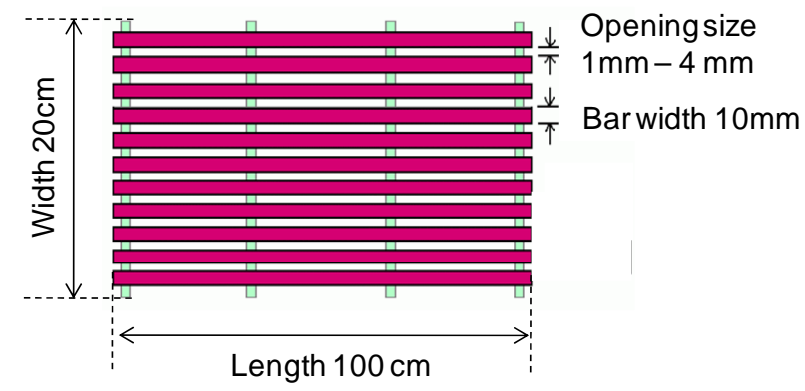

Fig. 5 plan view of debris flow brake

where $u$ is the depth-averaged flow velocity of the debris flow.

Mass conservation equations are

$$
\begin{aligned}
& \frac{\partial \rho h}{\partial t}+\frac{\partial(\rho u h)}{\partial x}=\rho_{w} w \\
& \frac{\partial \bar{c} h}{\partial t}+\frac{\partial(\bar{c} u h)}{\partial x}=0 \\
& \rho=\rho_{w}(1-\bar{c})+\sigma \bar{c}
\end{aligned}
$$

where $\rho$ is the density of the debris flow and $\bar{c}$ is the depth-averaged concentration of sediment particles in the debris flow.

The momentum conservation equation is

$$
\frac{\partial(\rho u h)}{\partial t}+\beta \frac{\partial\left(\rho u^{2} h\right)}{\partial x}=\rho g h \frac{\partial H}{\partial x}-\tau_{0}
$$

where $H$ is the elavation of the surface of the debris flow, $\beta$ is the momentum correlation factor $(=1.25)$, and $\tau_{0}$ is the bottom shear stress of the debris flow.

\subsection{Bottom shear stress}

The bottom shear stress of the one-dimensional depth-averaged debris flow can be expressed as follows [Egashira et al., 1989; 1997]:

$$
\tau_{0}=\tau_{y 0}+\rho_{w} f_{b} u^{2}
$$

where $\tau_{y 0}$ is the yield stress at the bottom of the debris flow and $f_{b}$ is the coefficient of friction.

Miyamoto and Ito [2002] proposed the following expression to approximate $f_{b}$ :

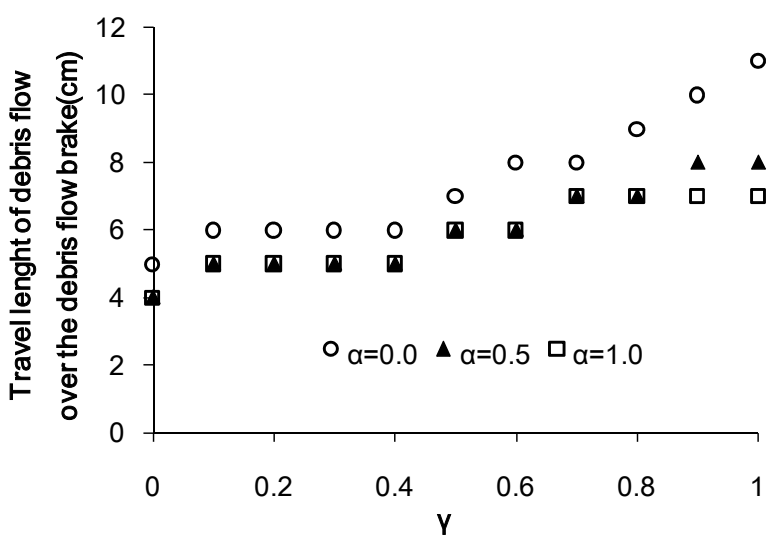

Fig. 6 Variation in travel length of debris flow over the debris-flow brake with change in $\gamma$

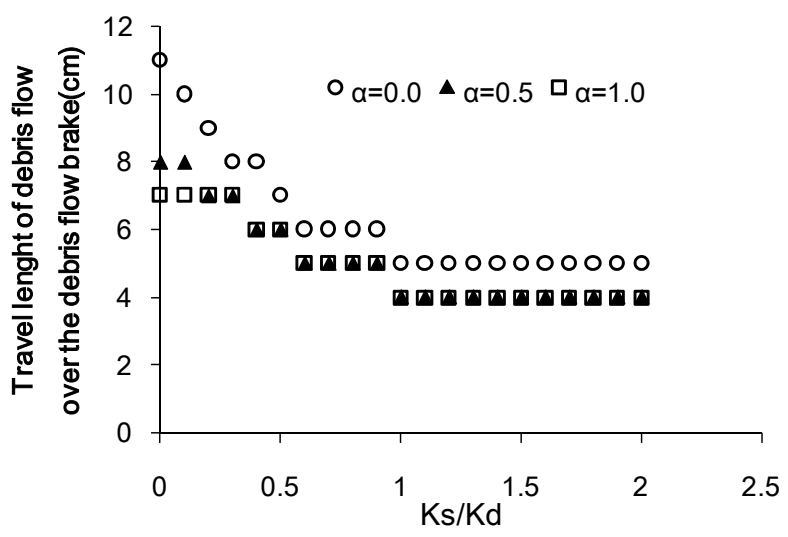

Fig. 7 Variation in travel length of debris flow over the debris flow brake with change in $\gamma$

$$
\begin{gathered}
f_{b}=\frac{25}{4}\left(f_{b}+f_{f}\right)\left(\frac{h}{d}\right)^{-2} \\
f_{b}=k_{g}\left(\sigma / \rho_{w}\right)\left(1-e^{2}\right) \bar{c}^{1 / 3} \\
f_{f}=k_{f}(1-\bar{c})^{5 / 3} / \bar{c}^{2 / 3}
\end{gathered}
$$

where $d$ is the diameter of gravel in the debris flow, $e$ is the coefficient of restitution $(=0.80)$ and $\mathrm{kg}$ and $\mathrm{kf}$ are empirical constants $(k g=0.0828, k f=0.16)$

In this study, Eqs (9) and (19)-(22) are used to evaluate the bottom shear stress $\tau_{0}$.

\subsection{Conditions of the numerical simulation}

The behavior of a debris flow in an experimental channel (length $335 \mathrm{~cm}$, width $20 \mathrm{~cm}$ and slope $19.0^{\circ}$ ) with a debris-flow brake installed horizontally at the downstream end of the channel $($ Figs. 4, 5) was simulated. The upstream side of the gate was filled with a mixture of gravel and water $(d=0.475 \mathrm{~mm}$, $\left.\varphi_{s}=38.8^{\circ}, V=7000 \mathrm{~cm}^{3}, \bar{c}=0.375, c * 0.52\right)$. A debris flow was generated when the gate was raised quickly. For the simulation, the parameters $\alpha$ and $\gamma$ were given values from 0.0 to 1.0 . 


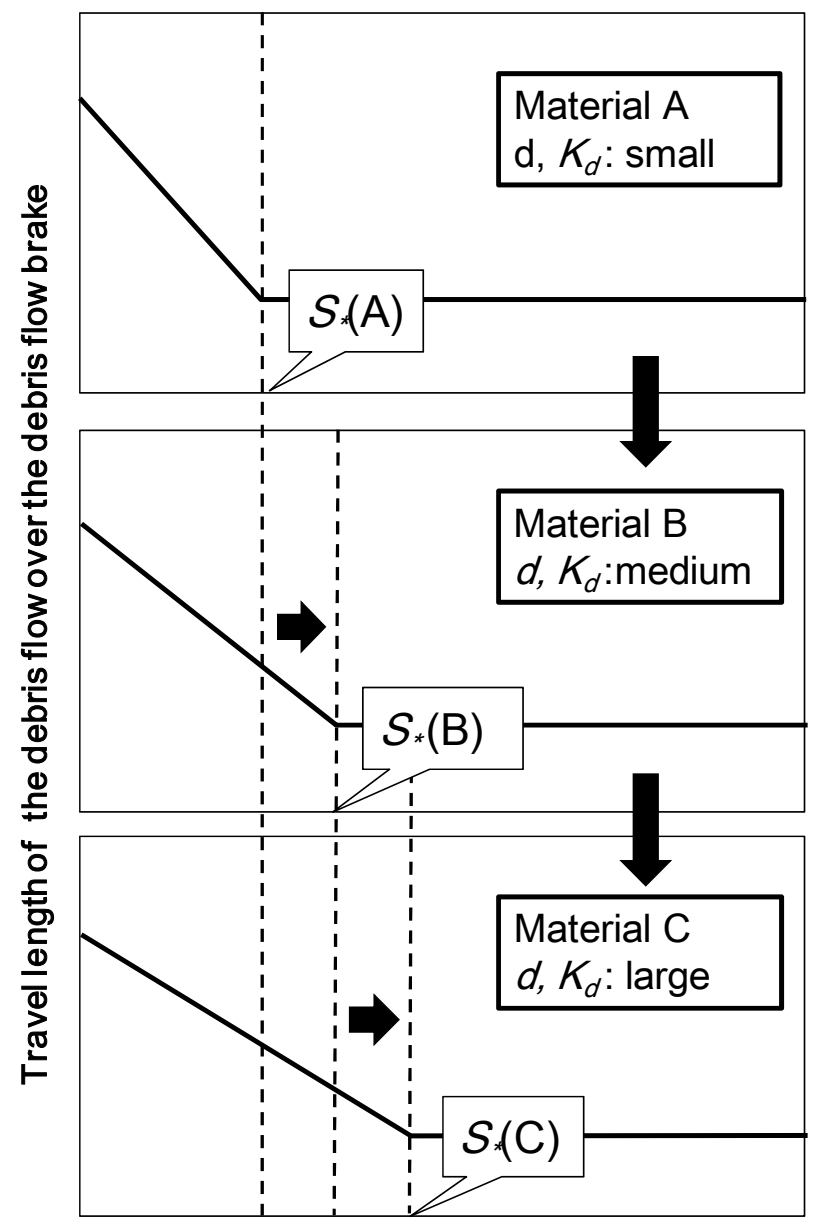

Opening size of the deck of debris flow brake

Fig. 8 Variation in travel length of debris flow over the debris flow brake with change in opening size of the deck of debris flow brake under different material condition expected from simulation results

\section{RESULTS OF SIMULATION}

Figure 6 shows that the travel length of the head of the debris flow over the debris-flow brake increased with increment in $\gamma$. Comparing $\alpha$ and $\gamma$, the effect of a change in $\gamma$ on the travel length is much greater than that of a change in $\alpha$. This means that the change in the pore-water pressure dominates the behavior of the debris flow on the debris-flow brake, rather than the change in the concentration of the debris flow due to the drainage of pore water through the debris-flow brake. The pore-water pressure changes instantly when a debris flow crosses the debris-flow brake, whereas the concentration of the debris flow changes gradually in proportion to the rate of drainage of the pore water through the debris-flow brake, and the change in concentration is small because the debris flow stops quickly on the
Table 1 Property of gravel used in experiments

\begin{tabular}{|c|c|c|c|}
\hline Material & $\begin{array}{c}\text { Diameter } \\
(\mathrm{mm})\end{array}$ & $\begin{array}{c}\Phi_{s} \\
\text { (degree) }\end{array}$ & $\begin{array}{l}\text { Density } \\
\left(\mathrm{g} / \mathrm{cm}^{3}\right)\end{array}$ \\
\hline Material A & 1.8 & 40.1 & 2.25 \\
\hline Material B & 3.4 & 41.1 & 2.5 \\
\hline Material C & 4.7 & 38.8 & 2.4 \\
\hline \multicolumn{4}{|c|}{ Table 2 Experimental condition } \\
\hline Case & Material & $\begin{array}{c}\text { Slope } \\
\text { (degree) }\end{array}$ & $\begin{array}{r}\text { Opening } \\
\text { size }(\mathrm{mm})\end{array}$ \\
\hline 1 & A & 19.7 & 0 \\
\hline 2 & A & 19.7 & 1 \\
\hline 3 & A & 19.7 & 2 \\
\hline 4 & A & 19.7 & 4 \\
\hline 5 & A & 19.7 & 8 \\
\hline 6 & B & 19.7 & 0 \\
\hline 7 & B & 19.7 & 1 \\
\hline 8 & $\mathrm{~B}$ & 19.7 & 2 \\
\hline 9 & B & 19.7 & 4 \\
\hline 10 & $\mathrm{~B}$ & 19.7 & 8 \\
\hline 11 & $\mathrm{C}$ & 19.7 & 0 \\
\hline 12 & $\mathrm{C}$ & 19.7 & 1 \\
\hline 13 & $\mathrm{C}$ & 19.7 & 2 \\
\hline 14 & $\mathrm{C}$ & 19.7 & 4 \\
\hline 15 & $\mathrm{C}$ & 19.7 & 8 \\
\hline 16 & $\mathrm{C}$ & 19.7 & 12 \\
\hline 17 & $\mathrm{C}$ & 16.0 & 0 \\
\hline 18 & $\mathrm{C}$ & 16.0 & 1 \\
\hline 19 & $\mathrm{C}$ & 16.0 & 2 \\
\hline 20 & $\mathrm{C}$ & 16.0 & 4 \\
\hline 21 & $\mathrm{C}$ & 16.0 & 8 \\
\hline 22 & $\mathrm{C}$ & 16.0 & 12 \\
\hline
\end{tabular}

debris-flow brake. This is why the change in pore-water pressure is dominate the behavior of the debris flow on the debris-flow brake.

Figure 7 shows the relationship between the travel length and the relative permeability, $K_{s} / K_{d}(=1$ $\gamma)$. For $K_{s} / K_{d} \leq 1$, the travel length decreases with increment in $K_{s} / K_{d}$, whereas for $K_{s} / K_{d}>1$, the travel length is constant.

The permeability of the deck of the debris-flow brake increases with the opening size of the deck. Here, it is assumed that the permeability of the pores in the gravel near the deck of the debris-flow brake depends only on the diameter of the gravel and that it is affected neither by the permeability of the deck nor by the concentration of the debris flow. Because the pores of gravel with larger diameters are thought to have greater permeability, i.e., $P_{d}$ for Material $\mathrm{A}<P_{d}$ for Material $\mathrm{B}<P_{d}$ for Material $\mathrm{C}$, variation in travel length of debris flow over the debris flow brake with change in opening size of the deck of debris flow brake under different material condition are expected as follows (Fig. 8).

The travel length of the head of a debris flow over 

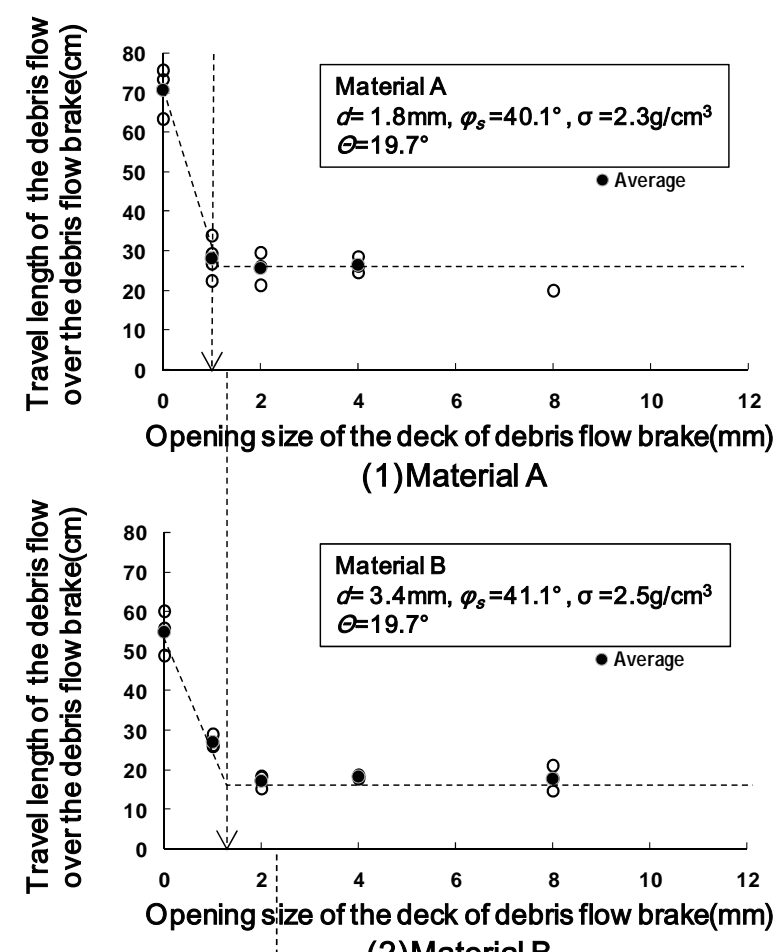

(2)Material B

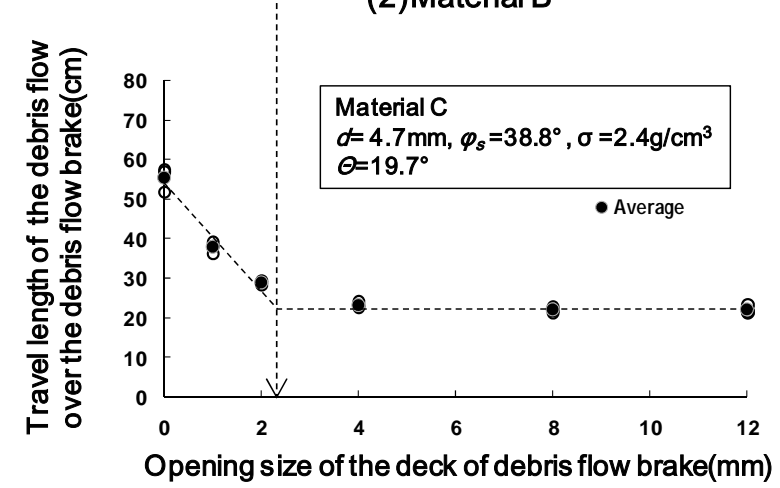

(3)Material C

Fig. 9 Variation in travel length of debris flow over the debris flow brake with change in opening size of the deck of debris flow braker under different material condition

the debris-flow brake increases as the size of openings in the deck increases. When size of openings in the deck exceeds the threshold opening size at which the permeability of the deck equals that of the pores of the gravel near the deck, the travel length has a constant value independent of the opening size.

The threshold opening size $S_{*}$, above which the travel length remains constant independent of the opening size, increases the diameter of gravel used as the material in the debris flow.

\section{EXPERIMENTS}

\subsection{Experimental devices and method}

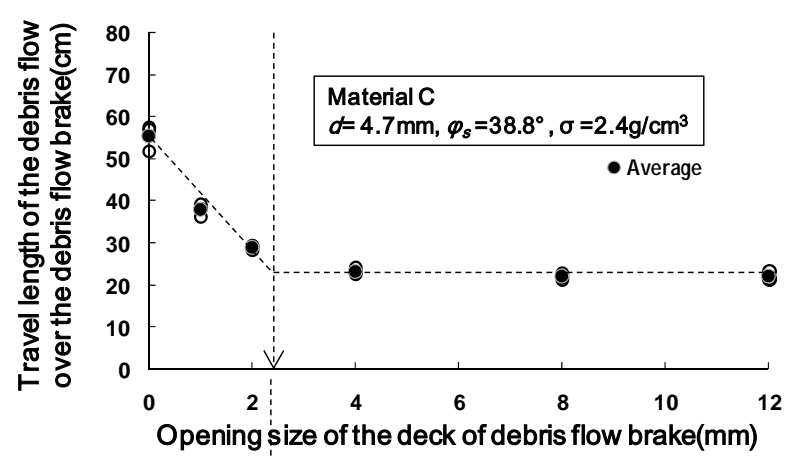

(1) $\theta=19.8^{\circ}$

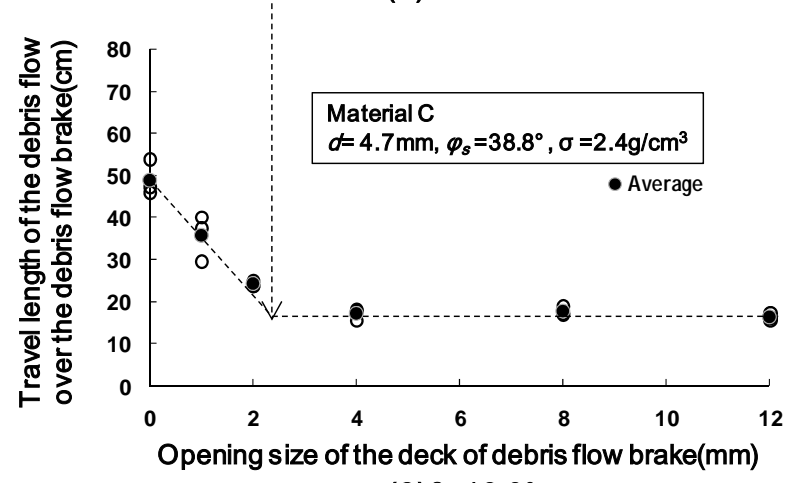

(2) $\theta=16.0^{\circ}$

Fig. 10 Variation in the travel length of debris flow over the debris flow braker with change in opening size of the deck of debris flow brake under different slope condition

An experimental channel(length $335 \mathrm{~cm}$, width $20 \mathrm{~cm}$ ) with a debris-flow brake(width $20 \mathrm{~cm}$, length $100 \mathrm{~cm}$ ) installed horizontally at the downstream end of the channel(Figs. 4, 5) was used. The upstream side of the gate was filled with a mixture of gravel and water $\left(V=7000 \mathrm{~cm}^{3}, C=0.375\right)$. A debris flow was generated when the gate was raised quickly. A digital video camera (Sony; DCR-TRV900) was installed at the debris-flow brake to measure the time displacement of the flow depth $h$ and velocity $u$. The travel length of the debris flow over the debris-flow brake was measured.

\subsection{Experimental condition}

Six types of wooden debris-flow brake with different strip openings were used (Fig. 5). The sizes of the openings in the deck of the debris-flow brake were $0,1,2,4,8$, and $12 \mathrm{~mm}$. Three types of nearly uniform gravel were used as debris-flow material (Table 1). The slope of the experimental channel was $i=16.0^{\circ}$ and $i=19.7^{\circ}$. The experimental conditions are shown in Table 2 For each condition, the experiment was repeated three times.

\subsection{Results of the Experiments}

Figure 9 shows the variation in the travel length of the debris flow over the debris-flow brake with 
changes in the size of openings in the deck of debris-flow brake under various material conditions. The travel length of the debris flow over the debris-flow brake decreased as the size of the openings in the deck increased. When the size of the openings exceeds a certain value, the travel length remained constant independent of the opening size.

Comparing $S_{*}$, the threshold opening size above which the travel length remains constant, among materials A, B and C, $S_{*}$ increases with the diameter of the material.

Figure 10 shows the variation in the travel length of the debris flow over the debris-flow brake with changes in the size of openings for different slopes. Compared $S_{*}$ for $i=16.0^{\circ}$ and $i=19.8^{\circ}, \mathrm{S}_{*}\left(i=16.0^{\circ}\right)$ and $S_{*}\left(i=19.8^{\circ}\right)$ are almost equal.

\section{DISCUSSION}

The results of the numerical simulations and experiments showed the same trends for both the relation between the travel length of a debris flow over the debris-flow brake and the size of and for that between the diameter of the gravel and the threshold opening size above which the travel length remained constant independent of the opening size. Therefore, our dynamic model of debris flow on a debris-flow brake is reasonable, and the behavior of debris flows on the debris-flow brake simulated using our model is essentially the same as the actual behavior of debris flows on a debris-flow brake. Therefore, the change in pore-water pressure dominates the behavior of a debris flow on a debris-flow brake rather than the change in concentration of the debris flow due to drainage of pore water through the debris-flow brake.

\section{CONCLUSION}

A simple dynamic model describing the behavior of debris flows on the debris flow brakes was developed that considers changes in pore-water pressure and sediment concentrations. Numerical simulations and experiments examining the behavior of debris flows on a debris-flow brake were conducted. The simulation and experimental results agreed, demonstrating the reliability of our model. Therefore, based on the results of the simulation, it is the change in pore water pressure that dominates the behavior of a debris flow on a debris-flow brake, rather than the change in the concentration of the debris flow due to drainage of pore water through the debris-flow brake.

\section{REFERENCES}

Egashira, S., Ashida, K., Yajima, H. and Takahama, J. (1989): Constitutive equation of debris flow, Annuals of the Disaster Prevention Research Institute, Kyoto Univ., 32B-2, pp.487-501 (in Japanese with English abstract).

Egashira, S., Miyamoto, K. and Itoh, T.(1997a): Bed-load rate in view of two-phase flow dynamics, Annual Journal of Hydraulics Engineering, JSCE, 41, pp.789-797 (in Japanese with English abstract).

Egashira, S., Miyamoto, K. and Itoh, T. (1997b): Constitutive equations of debris flow and their applicability, Proceedings of 1st International Conference on Debris-Flow Hazards Mitigation, New York: AXE, pp.340-349.

ICHARM (2008): Debris-flow dewatering brakes: a promising tool for disaster management in developing countries, International Center for Water Hazard and Risk Management Newsletter, Vol. 3, No. 3, pp. 10.

Imai, K., Miyamoto, N., Mizuyama, T. (1989): Test of a debris flow breaker at the Kamikamihori valley, Mt. Yakedake (Part-2), Journal of the Japan Society of Erosion Control Engineering, Vol. 42 No. 2 (163), pp. 16-20(in Japanese).

Izumi, I., Watanabe, M., Takemura, T., Mizuyama T. (1982): Test of a bottom infiltration screen in Ohsawa Fan, Mt. Fuji, Journal of the Japan Society of Erosion Control Engineering(Shin-sabo), Vol. 34, No. 3 (122), pp. 45-50(in Japanese).

Kiyono M., Miyakoshi H., Uehara S., Mizuyama T. (1986): Test of a debris-flow brake in Kamikami valley, Mt.Yake-dake, Journal of the Japan Society of Erosion Control Engineering, Vol. 39 No. 3 (146), pp. 15-19 (in Japanese).

Miyamoto, K. and Ito, T. (2002): Numerical simulation method of debris flow introducing the erosion rate equation, Journal of the Japan Society of Erosion Control Engineering, Vol. 55 No. 2 (241), pp. 24-35 (in Japanese with English Abstract).

Mizuyama, T. (2008): Structural countermeasures for debris flow disasters, International Journal of Erosion Control Engineering, Vol. 1, No. 2, pp. 38-43

Yazawa, A., Mizuyama, T., Morita, A. (1998): Experimental study on debris-flow control facilities, Civil Engineering Journal, 28, 8, pp. 9-14, (in Japanese) 